\title{
$\underline{\text { Aroma cross-modal interactions with texture and taste in dairy products }}$
}

\author{
Tournier, C, Sulmont-Rossé, C. and Guichard, E \\ UMR FLAVIC, Institut National de la Recherche Agronomique, 17 rue Sully, BP 86510, \\ 21065 Dijon Cedex, France. \\ guichard@dijon.inra.fr
}

\begin{abstract}
Model dairy desserts with different viscosity level were developed from a same composition and two levels of sweetness were obtained without changing the viscosity. Dairy desserts were equally flavoured with benzaldehyde. Thickness, sweetness and aroma intensity were evaluated by a consumer panel in two conditions: with and without nose-clips. Texture and aroma didn't interact but taste - aroma interactions were observed. Sweetness scores were increased when aroma was perceived whatever the viscosity level. Products with higher sucrose content were perceived as more intense in aroma. These reciprocal interactions are probably due to cognitive interactions.
\end{abstract}

Keywords: aroma, texture, taste, sensory interactions

It is nowadays admitted that sensory dimensions such as texture, aroma and taste may interact. These interactions may influence food perception and acceptability by consumers. To the best of our knowledge, most of the studies investigated only one type of binary interaction using different model systems composition. From the results it is not ever clear whether theses interactions occurred at a physicochemical, perceptual and/or cognitive level (Delwiche, 2004). In our consumer study, we investigated the reciprocal cross-modal interactions between aroma and texture or taste.

Custard desserts were prepared with skim milk, sucrose, tapioca starch and $\kappa$ carrageenan. An additional extra-shearing was applied at $5^{\circ} \mathrm{C}$ and during different time period in order to modify custard viscosity, without changing its composition. Previous steady shear and viscoelastic properties measurements showed that the longer the extra-shearing was, the lower the apparent viscosity and gel strength was. Moreover, in a second study, sweetness level of the more viscous custard dessert was modified. By replacing $1 / 2$ of sucrose content by lactose, sweetness level was modified without modification of rheological properties. Custard desserts were then flavoured with benzaldehyde $(10 \mathrm{ppm})$ and kept at $4^{\circ} \mathrm{C}$ for three days.

Sixty one consumers tasted the 3 viscosity level custard desserts with or without noseclips. For each sample, consumers rated the thickness (from liquid to thick), and sweetness (not sweet at all to very sweet) on $130 \mathrm{~mm}$ linear scales. Moreover they also rated the aroma intensity (not intense at all to very intense) when product were evaluated without nose clips. Products and rating scales were presented in a Latin square design among consumers. Data were analysed using a three-way analysis of variance with subject, viscosity level and aroma perception condition (with or without nose clips) as main factors and subject random. Finally, to complete the taste-aroma approach, the thickness, sweetness and aroma intensity of custard desserts made from two levels of sucrose were evaluated by another consumer panel.

\section{Aroma - texture cross modal interactions}

Concerning thickness perception, ANOVA results showed a significant effect of viscosity level $\left(\mathrm{F}_{(2,123)}=191.5, \mathrm{p}<0.0001\right)$. Thickness perception was found to increase linearly with apparent viscosity measured at $5^{\circ} \mathrm{C}$ and $50 \mathrm{~s}^{-1}$ (Fig.1). Moreover, thickness scores were not significantly different when products were evaluated with and without nose clips $\left(\mathrm{F}_{(1,62)}=0.72, \mathrm{p}=0.4\right.$ for aroma perception condition). Aroma intensity was not affected 
by the viscosity level $\left(\mathrm{F}_{(2,129)}=0.45, \mathrm{p}=0.6\right)$. Those results disagree with the decrease of benzaldehyde intensity observed when viscosity of model systems increased by changing the thickener content (Hollowood et al., 2002). In this last study aroma intensity could be more affected by product composition than by viscosity alone.

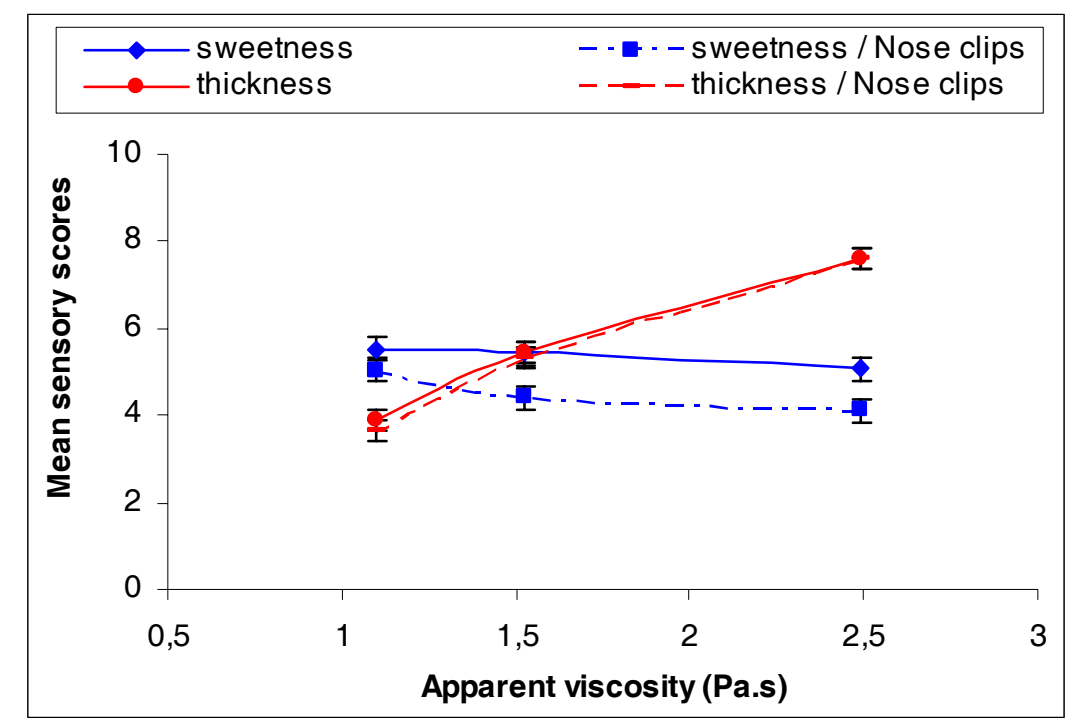

Figure 1. Mean sweetness and thickness scores and confidence interval (5\%) of custard desserts evaluated with (dotted line) or without (plain line) nose-clips, in function of apparent viscosity measured at $50 \mathrm{~s}^{-1}$ and $5^{\circ} \mathrm{C}$. All custard desserts have the same chemical composition; structure was varied with applied extra-shearing period.

\section{Aroma - taste cross modal interactions}

Sweetness scores were found to be significantly affected by aroma perception condition $\left(\mathrm{F}_{(1,61)}=16.77, \mathrm{p}<0.0001\right)$. Whatever the viscosity level, custard desserts evaluated with nose-clips were rated as less sweet than desserts evaluated without nose-clips (Fig. 1). The influence of sweetness on aroma intensity was then investigated in a complementary study with custard desserts made from two level of sucrose. Samples were compared with a T-test analysis. As expected sweetness decreased when sucrose level was decreased $\left(\mathrm{t}_{(1,28)}=\right.$ $3.73 \mathrm{p}<0.001)$ and the addition of lactose instead of suppressed sucrose had no impact on thickness perception $\left(\mathrm{t}_{(1,28)}=0.93, \mathrm{p}=0.3\right)$. Concerning aroma, the dessert with the higher sucrose level was perceived significantly more intense in aroma than the dessert with the lower sucrose level $\left(\mathrm{t}_{(1,28)}=-3.16, \mathrm{p}<0.001\right)$. In conclusion a reciprocal taste-aroma interaction was observed. This interaction may be attributed to a cognitive integration due to the association between benzaldehyde (pistachio, almond flavour in custard dessert) and sugar (Prescott, 1999).

\section{Cited literature}

Delwiche, J. (2004). The impact of perceptual interactions on perceived flavor. Food Quality and Preference, 15(2):137-146.

Hollowood, T. A., Linforth, R. S. T., and Taylor, A. J. (2002). The effect of viscosity on the perception of flavour. Chemical Senses, 27(7):583-591.

Prescott, J. (1999). Flavour as a psychological construct: implications for perceiving and measuring the sensory qualities of foods. Food Quality and Preference, 10(4/5):349-356. 